Young drivers, deterrence theory and punishment avoidance: A qualitative exploration

Lyndel Bates $^{\mathrm{a}^{*}}$ and Levi Anderson ${ }^{\mathrm{a}}$

${ }^{a}$ School of Criminology and Criminal Justice and Griffith Criminology Institute, Griffith University, Brisbane, Australia

176 Messines Ridge Road

MT GRAVATT QLD 4122

AUSTRALIA

Email:1.bates@griffith.edu.au

ORCID: 0000-0001-9898-2003

Twitter:@DrLyndelBates

Phone: 61737351429

${ }^{*}$ Corresponding Author

\title{
Acknowledgements
}

This research was supported by the Australian Government through the Australian Research Council's Discovery Early Career Researcher Award funding scheme (DE180100778).

Revision submitted to Policing: A Journal of Policy and Practice on 16 October 2019 


\title{
Young drivers, deterrence theory and punishment avoidance: A qualitative exploration
}

\begin{abstract}
Punishment avoidance occurs when a person commits an offence but is not punished for it. The aim of this paper was to explore how young drivers experience punishment avoidance. New drivers aged between 17 and 25 participated in 11 focus groups held in both metropolitan and regional areas in two Australian states: Queensland and Victoria. Thematic analysis identified that young drivers' experience punishment avoidance in one of three ways. Firstly, they can attempt to actively avoid punishment by engaging in deliberate actions to circumvent policing activities. Secondly, they can experience either direct or vicarious punishment avoidance of police enforcement. An example of this would be 'talking their way out of a ticket' after they had been caught by a police officer. Finally, their parents may help them avoid punishment by, for instance, paying the traffic fine on their child's behalf. This paper increases our understanding of how punishment avoidance occurs in practice.
\end{abstract}

Keywords: vicarious punishment avoidance; indirect punishment avoidance; road policing; novice drivers 


\section{Young drivers, deterrence theory and punishment avoidance: A qualitative exploration}

\section{Introduction and literature review}

Young drivers have higher crash rates when compared with older drivers (Blackman et al., 2008, Al Reesi et al., 2015, Greydanus, 2018). These higher crash rates occur for a number of factors including personality, lack of experience, more limited hazard perception skills and driving in higher risk situations such as with peer passengers or at night (Bates et al., 2014b). Younger drivers are more likely to be influenced by the behaviour of their parents and peers when compared with older drivers (Cassarino and Murphy, 2018). Additionally, high alcohol use increases the likelihood that young drivers will engage in unsafe driving behaviours (Begg et al., 2017). Given the significant economic and social impact of road crashes, greater attention from policing services is needed to help prevent them (Prenzler et al., 2015).

One countermeasure that has reduced crash rates for this group is graduated driver licensing (GDL) (Bates et al., 2014a). GDL systems gradually introduce young drivers to more risky driving situations. While there are jurisdictional variations in systems, in many cases, they include learner, intermediate and open phases (Bates et al., 2014a, Bates et al., 2018). GDL systems are present in Australia (Scott-Parker and Rune, 2016), New Zealand (Brookland and Begg, 2014), the United States (Williams et al., 2016) and Canada (Poirier et al., 2018). GDL systems reduce young driver crashes by limiting their exposure to more risky driving situations (Bates et al., 2014a). The reduction in crashes that occurs after a GDL system is introduced is influenced by the evaluation methodologies used and the age group of novice drivers to which it applies (Shope and Molnar, 2003, Zhu et al., 2015). Both Queensland and New South Wales (Australia) had existing, but different, GDL systems prior to 2007 that included a learner, provisional and open phase. An evaluation of the 
strengthened GDL system that was introduced into Queensland in mid-2007 resulted in reduced road crashes (Senserrick et al., 2018).

\section{Young driver offending}

Within GDL systems young drivers commit road offences, although the rate at which this occurs differs between jurisdictions. For instance, New Zealand research indicates that compliance with GDL restrictions is limited with approximately $25 \%$ of learner drivers driving without supervision. Within the intermediate phase, over $50 \%$ indicated that all or most of their nighttime driving was unsupervised and thus in violation of the rules of the New Zealand GDL system. Almost $80 \%$ of the sample reported that they drove with passengers in their vehicle in contravention of the law (Brookland and Begg, 2014). In contrast, research from New Jersey indicates that 8.3 per cent of young driver trips did not comply with a peer passenger restriction and 3.1 per cent of young driver trips did not comply with a night driving restrictions (Curry et al., 2017). Lower numbers of young drivers report being detected by police, as opposed to actually committing a driving offence. This highlights the difference between the number of offences that are detected by police resulting in a traffic infringement and the number of offences that are actually committed by young drivers. For instance, in Queensland, approximately $12 \%$ of provisional licence holders indicated in an online survey that they had been detected by police committing a driving offence (ScottParker et al., 2013). In contrast, official data from California indicated that 55\% of new 16 and 17-year-old drivers had a recorded traffic violation within the first three years of driving (Chapman et al., 2014). Enforcement is a key mechanism used to alter driver behaviour (Bates et al., 2012, Bates, 2014, Castillo-Manzano et al., 2019) including for young drivers (Scott-Parker et al., 2015). Evidence suggests that reducing offending by drivers may assist in reducing the injuries that result from road crashes (Factor, 2014). 


\section{Deterrence theory}

It is important to ensure that individuals adhere to road laws to improve individual and community road safety (Fleiter et al., 2013). However, given that breaking the road rules may reflect wider offending behaviour (Rose, 2000, Nunn, online first, 2018), it also provides an opportunity to indicate to the community a police presence and possibly reduce wider offending behaviour.

Compliance occurs when people agree to the requests of others (Wortley, 2011). Compliance theory suggests that this agreement is a planned decision rather than an 'automatic' behaviour. There are numerous motivations for compliance, that are not merely cumulative, but also interact with each other (Etienne, 2011). One aspect of an interaction with authority that affects levels of compliance is the use of procedural justice. Research has indicated that when authorities treat people fairly during interactions, they are more likely to comply (e.g. Murphy and Tyler, 2008, Reisig et al., 2014), although these findings may not be consistent across all contexts (e.g. Woo et al., 2018).

Despite this, deterrence theory underpins much of road policing (Bates et al., 2012, Freeman et al., 2015, Tudor-Owen, in press) and, was used as the basis of initiatives such as Random Breath Testing introduced within Australia in the 1970s and 1980s to detect and prevent drink driving (Homel, 1988b). Deterrence theory proposes that individuals avoid offending if they fear the perceived consequences of doing so (Davey and Freeman, 2011).

Classical deterrence theory includes three elements: certainty, swiftness and severity (Freeman et al., 2016). Certainty refers to the perceptions that an individual will be caught if they commit the offence. Swiftness is the idea that punishment should occur soon after the offence is committed while severity refers to the idea that the consequences of committing the crime should be serious enough that it outweighs the rewards. The deterrence of a certain 
behaviour is achieved when the potential offender believes that there is relative certainty that their offence will be detected and they will receive a severe punishment as a result.

Research in the road enforcement field has indicated that certainty is the most important factor in predicting the deterrent effect of speed cameras (Freeman et al., 2017b) and the prevention of speeding behaviours (Truelove et al., 2017). There is some suggestion that the use of mass-media publicity can increase the perception that it will be certain that individuals will be caught while offending on the road (Homel, 1988a) although actual police enforcement is required to support the media campaign (Elliott and Broughton, 2004).

There has been limited research that has specifically focused on deterrence theory and young drivers. Survey research with two different samples of young drivers conducted in Queensland, Australia indicates that police enforcement does not deter young drivers from offending on the road (Allen et al., 2017, Bates et al., 2017). Bates et al. (2017) found that reporting greater exposure to police was associated with lower levels of compliance with the road rules. They surmised that one possible reason for this was an 'emboldening effect'. An emboldening effect occurs when individuals experience punishment avoidance or rationalise punishments received to minimise the deterrent effects in a way that does not reduce the likelihood of future offending (Piquero and Pogarsky, 2002).

Allen et al. (2017) identified that formal deterrence mechanisms, operationalised as police within their study, did not affect young drivers' behaviour on the road. What they did identify was that informal deterrence, or parents, did have an effect. This informal deterrent effect was mediated by the young driver feeling shame regarding their behaviour. This suggests that there is a need to develop a greater understanding of how deterrence, and the various aspects contained within the theory, affect young driver behaviour. 


\section{Punishment avoidance}

Stafford and Warr (1993) reconceptualised deterrence theory and introduced the idea of punishment avoidance. Punishment avoidance occurs when an individual commits an offence but is not punished for it (Stafford and Warr, 1993, Piquero and Paternoster, 1998). It increases the likelihood of offending because, for rational individuals, it decreases the perceptions regarding the certainty and severity of punishment (Stafford and Warr, 1993, Paternoster and Piquero, 1995). Within road policing, punishment avoidance is particularly relevant given that the chances of being apprehended for some driving offences is low (Freeman et al., 2015).

Punishment avoidance is a key influential factor in predicting whether an individual will re-offend (Paternoster and Piquero, 1995, Piquero and Paternoster, 1998, Freeman and Watson, 2006, Szogi et al., 2017). Within the road policing field, survey research undertaken in Australia with samples of drivers of all ages indicates that experiences of punishment avoidance increase the likelihood that drivers will drug drive (Watling et al., 2010, Armstrong et al., 2018), drink-drive (Freeman and Watson, 2006, Szogi et al., 2017) and speed (Freeman et al., 2017a).

Bates et al. (2017) used a survey with a convenience sample of young drivers to explore the usefulness of deterrence theory in explaining two types of offending behaviours. The first is fixed offending which are those that occur before someone enters the vehicle and remains for the entire journey, such as drink driving. The second type is transient offending which occur while driving but is not present for the entire journey such as speeding (e.g. drivers may speed at times and not others throughout a single trip). The analysis indicated that punishment avoidance was not significant for either offence type at the .05 level although it approached significance $(p=.05)$ for transient offences. 
Most people are likely to have a mixture of direct and vicarious experience with punishment avoidance (Stafford and Warr, 1993). The evidence for vicarious punishment avoidance, which is the observation and sharing of the punishment avoidance experiences of others (Piquero and Pogarsky, 2002), is more mixed. For instance, while Szogi et al. (2017) identified that direct punishment avoidance was the strongest predictor of drink driving in a survey of Queensland drivers, they did not find an effect for vicarious punishment avoidance. In contrast, vicarious punishment avoidance appears to increase the likelihood that drivers will drug drive (Watling et al., 2010).

A scoping review conducted by Bates et al. (2019) revealed that there has been limited qualitative exploration of the enforcement of young drivers within GDL systems using deterrence theory as a framework. However, Truelove et al. (2019) did explore young driver compliance, or adherence to road laws, with GDL rules with a deterrence framework. They conducted 11 focus groups within metropolitan areas in south-east Queensland. Their participants included individuals aged between 17 and 25 years and on a Provisional 1 (P1), Provisional 2 (P2) or open licence. While they briefly identified that punishment avoidance was present for young drivers, they indicated that there were many rules that young drivers did not know and were therefore unintentionally breaking (Truelove et al., 2019).

This study builds upon the existing literature, much of which is survey-based, in order to qualitatively explore the role of punishment avoidance in young driver offending. This study occurs in two jurisdictions, Queensland and Victoria, which have different licensing systems. While both of these states, Queensland and Victoria, have GDL programs, they differ based on the ages required to enter certain stages and the restrictions placed on young and novice drivers. 


\section{Method}

\section{Context}

Queensland introduced a strengthened GDL program in 2007 which allows young people to obtain a Learner license at 16 years, P1 license at 17, P2 license at 18 and an open or unrestricted license at 20 years (see Table 1). To progress from an L to a P1 in Queensland, apart from being 17, drivers must also complete one hundred hours of supervised driving. Drivers are required to complete an online hazard perception test and be a minimum of 18 years to progress from a P1 to a P2 license. Restrictions within the Queensland GDL system include a zero blood-alcohol limit, displaying appropriate plates on the vehicle to indicate license status, restrictions on the number of peer passengers during certain time periods (P1 drivers) and restrictions around the use of mobile phones even when connected to hands-free devices (P1 drivers). In Queensland, if you are over the age of 23 when you obtain your P1 licence, your P2 phase will be shortened from two years to only one year.

Victoria issues L licences to drivers aged at least 16 years old. However, drivers are not able to drive unaccompanied until they are 18 years of age. In Victoria, following the learner phase drivers progress to probationary licenses as opposed to being called provisional licenses within Queensland. Both of these are intermediate licenses within the GDL system. The supervised hour requirement for drivers in Victoria to progress from $\mathrm{L}$ to $\mathrm{P} 1$ is one hundred and twenty hours. Restrictions within the Victorian GDL program include a zero blood-alcohol limit, displaying appropriate plates on the vehicle to indicate license status, being prohibited from towing a trailer or another vehicle, restrictions on the number of peer passengers aged 16 to 22 (P1 drivers) allowed in the vehicle and restrictions around the use of mobile phones even when connected to hands free devices (P1 drivers). Siblings, stepsiblings, partners and spouses are not counted as a peer passenger. In Victoria, if you are over 
the age of 21 when you first pass your practical driving test, you will skip the P1 phase and start on the P2 phase which must be held for three years.

Table 1: Queensland and Victorian (Australia) P restrictions

\begin{tabular}{l|l} 
Queensland & Victoria \\
Provisional One (P1) & Probationary One (P1) \\
\hline Minimum age of 17 years & Minimum age of 18 years \\
Peer passenger restrictions & Peer passenger restrictions \\
Zero blood alcohol concentration & Zero blood alcohol concentration \\
Display red P plates on vehicle & Display red P plates on vehicle \\
No mobile phone usage (even using & No mobile phone usage (even using \\
Bluetooth or hands-free) & Bluetooth or hands-free) \\
High-powered restrictions & High-powered restrictions \\
& Restriction on towing trailers/caravans \\
& Probationary Two (P2) \\
Provisional Two (P2) & Minimum age of 19 years \\
\hline Minimum age of 18 years & Zero blood alcohol concentration \\
Zero blood alcohol concentration & Display green P plates on vehicle \\
Display green P plates on vehicle & High-powered restrictions \\
High-powered restrictions & No mobile phone usage (even using \\
& Bluetooth or hands-free)
\end{tabular}

\section{Participants}

Participants in this study were aged between 17 years of age in Queensland and 18 years of age in Victoria and 25 years of age. All participants held either a P1 or P2 licence. Of the 31 participants, $45.16 \%$ were male. Participants were recruited through local community and university social media pages as well as using local university announcements.

\section{Procedure}

The focus groups used semi-structured questions to explore the key constructs within the study: punishment avoidance and compliance with road laws. Participants were asked about their perceptions of police enforcement of road laws, the likelihood of being caught by police and whether parents had the ability to influence provisional drivers and their adherence to the 
law. Given the semi-structured nature of the focus groups, facilitators were able to probe participant responses to further explore issues. The decision to cease conducting focus groups was made after 11 sessions as saturation had been reached amongst the young driver population in both states.

With the agreement of all participants, every focus group was audio-recorded and transcribed. Ethical clearance was obtained from the Griffith University Human Research Ethics Committee prior to conducting the focus groups (GU/Ref: 2018/150).

At the start of each focus group, participants were provided with both an information sheet and a consent form. The information sheet outlined the perceived potential risks to the participants and explained that while the content of the focus groups may discuss illegal or non-compliant behaviour, it was not the objective of the focus groups to target this information. All participants remained anonymous and no illegal driving behaviour was disclosed to police.

Of the focus groups, $(\mathrm{n}=11) 45.45 \%$ were in Queensland and $54.55 \%$ in Victoria. In order to include a mixture of both metropolitan and regional participants, focus groups were held on university campuses in Brisbane and Cairns (Queensland) and Melbourne, Bendigo and Wodonga (Victoria). Of these focus groups, 63.63\% of them were held in regional locations. The researchers allowed approximately an hour for each focus group. All focus groups were conducted by the same two researchers to maintain consistency throughout the data collection process.

\section{Analysis}

The recorded focus groups were transcribed verbatim to facilitate analysis. The transcripts were used to undertake an inductive thematic analysis (Tuckett, 2005). The inductive thematic analysis was employed to discover the common themes among transcripts with 
regards to punishment avoidance. The analysis was not informed or structured around any framework or preconceived themes. Both researchers analysed the transcripts together. This ensured consistency in developing the themes and codes from within the transcribed data. Where disagreement occurred, the researchers discussed the issues until resolved. Themes were identified when concepts were frequently expressed or discussed with a substantial amount of intensity by a majority of the participants.

\section{Results}

The focus groups suggest that drivers experience punishment avoidance through three different mechanisms (a) active punishment avoidance (b) direct and vicarious punishment avoidance of police enforcement and (c) parental punishment avoidance.

\section{Active Punishment Avoidance}

Active punishment avoidance occurs when young drivers deliberately and consciously take actions to avoid police and their operations in order to circumvent punishment. The focus groups indicated that one way that provisional drivers did this was through the removal of the 'P' plates, which when displayed on their vehicle, indicate their licence status.

'Often people just take off their P plates so - and pretend they're, like, full[y] licensed. So they can carry more people.' (Male, Queensland, Regional)

By pretending that they are fully licensed drivers, the young people that participated in the focus groups perceive that they are able to break road laws that apply to their licence type such as restrictions on the number of peer passengers at particular times of the day. Thus, they are breaking the law in order to avoid police (by not displaying P plates) while they commit further offences compounding the seriousness of their actions. 
Another way that young people appear to actively avoid punishment is by selecting the roads which they travel on and through the close relationships formed between the community and police in small rural areas. This is supported by drivers from rural areas as they discuss their use of alternate routes to avoid commonly policed areas and a relationship with the local police within the regional community that they believe will allow them to circumvent punishment should they be intercepted breaking the law. Simply put, they believe that they can identify roads where limited police enforcement occurs or circumvent punishment through a 'small town' relationship with law enforcement.

'I know. I live in Horsham, so on the way back, I know that there's not - the only place that you see police is around St Arnaud. So, like, before that, and then after, you're not likely going to see them at all.'(Female, Victoria, Regional)

'It's like when I'm driving home on the highway, the bits that I know have speed cameras on it, I'll be a lot more cautious than just like the back-road strips.' (Male, Queensland, Metropolitan)

'...so there are roads, back roads and no one travels on them, so [I] tend not to care as much and never been caught, so I'm going to keep doing it.' (Female, Victoria, Regional)

Focus group participants highlighted the benefits of actively avoiding punishment. They perceived that these actions enabled them to engage in illegal driving behaviours. For instance, they were able to carry more peer passengers:

'I know it's quite a common thing back where I live in Sydney. Often people just take off their P plates so - and pretend they're, like, full licence. So they can carry more people.' (Male, Queensland, Regional)

They also believed they could engage in speeding behaviours. 
'... it's like a rural road and the speed limit's 110 , and there's no one on it, like you know, no one's going to see if you do 120...' (Male, Victoria, Regional)

Thus, it appears, that by participants believing they can take actions to avoid punishment by police, they are more likely to engage in illegal driving behaviours.

'You finish your movie and then you had some dinner and then you're like, oh, it's late now. They could go, oh, it's okay, we'll just take the back streets or something. Mainly but then other people just really don't care. They just - they are willing to take the risks.' (Female, Queensland, Regional)

\section{Direct and vicarious punishment avoidance of police enforcement}

Focus group participants discussed situations where they, or people they knew, had been caught by the police while engaging in illegal driving behaviours and yet the officer had made the decision not to punish the behaviour. In cases that involved the participant themselves, they appeared to have experienced direct punishment avoidance:

\footnotetext{
'This one time I came home for our town's races and I was driving home the next morning and a local cop who I know pulled me over and then when he pulled me over and saw that it was me, like oh crap, I better not breatho [roadside breath test] you because you're definitely going to blow over. So I reckon they know the rules, but they're just a bit lax on them [regional police].' (Male, Victoria, Metropolitan)
}

When they had witnessed or heard about it occurring to others, they seemed to have experienced vicarious punishment avoidance. For instance, one participant described how another individual had convinced the police officer to not issue an infringement for speeding. This participant then indicated that knowing this occurred and that they had avoided punishment, he believed that he could do the same (Male, Victoria, Regional). Other participants were able to recount other instances of vicarious punishment avoidance.

\footnotetext{
'I was in the car with my dad when he was speeding and he talked himself out of a ticket.' (Male, Victoria, Regional)
} 
'But like you hear stories of people getting away with speeding tickets like because some of my mates, they just talked their way out of it.' (Female, Victoria, Metropolitan)

'I was in a car with my friend, she was on her green Ps, and she was doing 17 over the speed limit, and the same happened - the cop just gave her a warning and stuff, and then she just kept going - she didn't get a fine or anything, and it didn't really phase her or anything - like she still speeds and stuff.' (Female, Queensland, Metropolitan)

At times, it appears that young drivers can be both punished and experience punishment avoidance. One participant talked about how he had committed two driving offences simultaneously. When he was caught he was punished for one but not the other:

'I'm a New South Wales P plater, so I'm green Ps and I've had my Ps since I was 17, and I could have got my full licence last April but I've moved here and just been pretty lazy about it. But over the Good Friday weekend, I was done speeding and got away with a DUI, that one, just because she knew that she was going to take my licence anyway, she was like, oh, well, I won't do your DUI as well. So I lost my licence for three months and by the time I get it back I'll just go get my fulls [open license] and back on it.' (Male, Victoria, Metropolitan)

When caught by the police, participants indicated that they know young drivers are prepared to deceive a police officer to avoid punishment:

'I know my sister had a couple of friends in the car once and she just said, oh yeah, this is my sister. The police officer bought it somehow, but - yeah, she was just like this is my sister, because, oh, [she goes] she doesn't have any proof, but she's my sister and you've got to believe me, and he did.' (Female, Queensland, Regional)

'Oh just my sister was talking about her friend and she didn't have P plates on, and then the first time she got pulled over she just said she was going to get them.' (Female, Queensland, Metropolitan)

The consequences of direct or vicarious punishment avoidance appear similar to active punishment avoidance. Young drivers appear to continue to engage in illegal driving 
behaviours:

'She even said to me if you ever got pulled over just tell them that's your sister, your brother. They can't tell you it's not. Yeah, I think it made her do it a few more times.' (Female, Queensland, Regional)

'I feel like yeah because they think well they didn't get a fine, they're like oh well, I can just get away with it and stuff, it doesn't really matter.' (Female, Queensland, Metropolitan)

\section{Parental punishment avoidance}

Even when young drivers are punished by police, in some cases parents can facilitate punishment avoidance for young drivers. Participants were asked about their experience, or the experiences of young drivers they know, with parents who assume responsibility for a camera detected offence committed by the young driver. When a speeding infringement notice is being issued using camera detected enforcement, it is possible that parents assume responsibility for the offence in order to spare their child from financial costs or demerit points ${ }^{1}$ that will be recorded on the driver's license. Assuming penalties on behalf of another driver is an offence itself within Australia as vehicle owners are supposed to sign a statutory declaration indicating the driver of the vehicle if it was not them.

'I know my parents would do that for me if that was the case but it hasn't happened yet.'

(Female, Queensland, Regional)

Participants appeared aware that, while some parents may help them avoid punishment, there were limits to the frequency with which this would occur. It appears that most young drivers expected that their parents would do this once.

\footnotetext{
${ }^{1}$ Demerit points are applied to a licence when a person is caught by police committing a traffic offence; once you accumulate a certain number of demerit points, a licence saction is applied. Demerit points occur in conjunction with financial penalties.
} 
'I reckon my parents would, but not for more than one time. It would be, like, a one-time thing.' (Male, Queensland, Regional)

'I don't know. I think it would be more like - if, considering the circumstance, I guess, I don't know. Because maybe next time it happened again I would take the blame but if it was like, just the first time, they'd probably do it for me.' (Female, Queensland, Regional)

Some participants indicated that their parents would help them avoid some, but not all, punishment. For instance, one participant indicated that though it had not yet happened, they believed their parents would take responsibility for the offence and thus accumulate the demerit points on their licence. However, the young person would still be expected to pay the financial penalty that accompanied the infringement (Male, Victoria, Metropolitan). Another participant indicated that his parents would pay for his traffic infringement as he did not have a job and therefore would be unable to pay the financial component of the penalty (Male, Queensland, Metropolitan).

\section{Discussion}

This study has explored the way in which punishment avoidance influences the behaviour of young novice drivers in GDL systems. The findings suggest that punishment avoidance occurs for this group in 3 ways (a) active punishment avoidance (b) direct and vicarious punishment avoidance of police enforcement and (c) parental punishment avoidance. The first two types of punishment avoidance appeared to encourage young drivers to continue engaging in illegal driving behaviours. This is consistent with survey research indicating that punishment avoidance will encourage a range of illegal driving behaviours (Freeman and Watson, 2006, Watling et al., 2010, Freeman et al., 2017a, Szogi et al., 2017, Armstrong et al., 2018). 
This study identified that one method of actively avoiding punishment was to drive on roads that young people believed were not enforced as regularly. This is consistent with the previous research that identified that young drivers believe they are aware of roads that police are likely to be conducting enforcement operations on and therefore they are able to use alternate routes to avoid police detection of offences (Bates et al., 2016). There was some indication from the current study that the use of alternate routes may be a more effective punishment avoidance strategy in regional areas.

Another behaviour by young drivers which they perceived allowed them to avoid punishment was the removal of $\mathrm{P}$ plates. Almost all participants either had removed the $\mathrm{P}$ plates from their vehicles themselves or had witnessed another removing the plates. Previous research suggests that another reason for this is the perception that police target young drivers, particularly those who are still on an intermediate licence (Bates et al., 2017). However, research conducted in New Jersey in the United States of America did not identify that the introduction of a requirement for new drivers to display a decal on their vehicle to indicate their licence status had an effect on compliance rates with night time driving or passenger restrictions (Palumbo et al., 2018). However, compliance rates with both of these driving restrictions were high before the introduction of the decal requirement.

As noted by Stafford and Warr (1993) most people have experienced both direct and vicarious punishment avoidance. This is supported by the current study with participants able to recount situations where they, or someone they knew, had been caught offending but not punished. The focus groups indicated that their vicarious experiences of punishment avoidance occurred with a range of people including both peers and parents. This is consistent with research suggesting that many provisional drivers are able to talk the police officer out of giving them a ticket (Scott-Parker et al., 2011). 
While previous research has identified that parents will accept the penalty for traffic offences on their children's behalf (Scott-Parker et al., 2011), the current study explored this in greater detail. For instance, this study identified that young drivers were aware that their parents would place limits on how often they would do this. They also indicated that parents may only take part of the penalty depending on the circumstances. Parents may assist the child with avoiding the financial component of the penalty if they are unemployed or, alternatively, accept the demerit points associated with the penalty in order to ensure that the young driver is able to continue to drive. It is possible that a primary motivator for parents in facilitating young driver punishment avoidance is the loss of mobility that occurs for their child if they no longer hold a drivers licence. However, when parents facilitate punishment avoidance for their children they may be limiting the deterrent effect that occurs for young drivers on intermediate licences (Poirier et al., 2018).

Overall, this study indicates that the concept of punishment avoidance within deterrence operates in different ways and that there are different mechanisms that can be used to circumvent the consequences of illegal road behaviours. Given that punishment avoidance appears to increase the likelihood of future road offending (e.g. Watling et al., 2010, Szogi et al., 2017, Truelove et al., 2017, Armstrong et al., 2018), it is important to limit both the actual, and perceived punishment avoidance, that occurs. As punishment avoidance operates in different ways, countermeasures need to reflect this. For instance, when considering direct punishment avoidance, increasing the certainty of being caught offending may be useful. One example where this has occurred previously is in the area of random breath testing. Research suggests that as the number of random breath tests increases, the number of alcohol-related crashes falls because the perceived risk of detection is higher (Ferris et al., 2013). Perceptions regarding the certainty of being caught could also be increased through the use of public media campaigns when combined with traffic enforcement (Elliott and Broughton, 2004). It 
is important that interactions between police and individuals occur in a manner that ensures that it strengthens the legitimacy of the policing agency. The use of procedural justice within these types of interactions has been shown to increase legitimacy (e.g. Mazerolle et al., 2013, Akinlabi, 2017).

Additionally, there may be a need to use an appropriate intensity level of enforcement to ensure that drivers perceive that they cannot avoid punishment. For instance, de Waard and Rooijiers (1994) identified that stopping every 6th speeding offending was required in order to maintain reductions in mean travelling speeds after a period of enforcement.

In relation to direct and vicarious punishment avoidance of police enforcement, it is important that when police detect a traffic offence they ensure that the driver is punished. They should not allow young drivers to 'talk themselves out of a ticket' which research has shown does occur (Scott-Parker et al., 2011). Parents should also ensure that they do not role model punishment avoidance behaviours to their children. Additionally, parents should not take penalties, or partial penalties, for their children's driving offences. If police agencies detect this occurring, they should ensure that both parties are punished for this behaviour.

This study was one of the first to qualitatively explore how young drivers perceive punishment avoidance. While the study used a convenience sample, participants were recruited from two Australian states and from both metropolitan and regional locations. This ensured the representation of a greater range of young drivers despite the limited sample size. However, it does limit the ability to generalise the results of this study to other locations meaning that further research is needed in other jurisdictions and with larger sample sizes. A further limitation was the small sizes within some focus groups, particularly in the smaller towns. While every effort was made to ensure that focus groups consisted of four or more individuals, not all registered participants attended. This meant that a few groups consisted of two people. 
Given the shortage of theoretically informed research regarding the enforcement of young driver behaviour (Bates et al., 2019), there is a need to conduct more work in this area. This research should broaden the theoretical perspective beyond punishment avoidance and deterrence theory and consider alternative frameworks. These could include procedural justice (e.g. Mazerolle et al., 2013, Mazerolle et al., 2015, Sargeant et al., 2018) and third party policing (e.g. Mazerolle and Ransley, 2005, Mazerolle, 2014, Webster, 2015, Belsham et al., in press) which have both been used in other enforcement contexts. Additionally, further research should evaluate how various countermeasures can reduce the effect of different types of punishment avoidance.

\section{Conclusion}

While the most common framework applied to road policing is deterrence theory, this paper shows that when young drivers experience punishment avoidance it undermines both policing and road safety efforts. Some young drivers will commit traffic offences, and as shown in this study, are able to avoid being punished for it. This research suggests that they are able to avoid punishment through three mechanisms: (a) active punishment avoidance (b) direct and vicarious punishment avoidance of police enforcement and (c) parental punishment avoidance. Each mechanism appears to operate slightly differently from the others and may, therefore, require different countermeasures in order to reduce the perceptions that it is possible to avoid being punished for road offences. By doing so, this paper adds to our understanding of how the punishment avoidance concept is operationalised and provides an evidence base that can be used to make policy decisions regarding young driver enforcement operations. 


\section{References}

Akinlabi, O., 2017. Young people, procedural justice and police legitimacy in Nigeria. Policing and Society, 27, 419-438.

Al Reesi, H., Al Maniri, A., Al Adawi, S., Davey, J., Armstrong, K. \& Edwards, J., 2015. Prevalence and Characteristics of Road Traffic Injuries Among Young Drivers in Oman, 2009-2011. Traffic Injury Prevention, 17, 480-487.

Allen, S., Murphy, K. \& Bates, L., 2017. What drives compliance? The effect of deterrence and shame emotions on young drivers' compliance with road laws. Policing and Society, 27, 884898.

Armstrong, K., Watling, C. \& Davey, J., 2018. Deterrence of drug driving: The impact of the ACT drug driving legislation and detection techniques. Transportation Research Part F: Traffic Psychology and Behaviour, 54, 138-147.

Bates, L., 2014. Procedural Justice and Road Policing: Is it important? 2014 Australasian Road Safety Research, Policing \& Education Conference. Melbourne.

Bates, L., Allen, S., Armstrong, K., Watson, B., King, M. \& Davey, J., 2014a. Graduated driver licensing: An international review. Sultan Qaboos University Medical Journal, 14, 403-412.

Bates, L., Darvell, M. \& Watson, B., 2017. Young and unaffected by road policing strategies: Using deterrence theory to explain provisional drivers' (non)compliance. Australian and New Zealand Journal of Criminology, 50, 23-38.

Bates, L., Davey, J., Watson, B., King, M. \& Armstrong, K., 2014b. Factors contributing to young driver crashes: A review. Sultan Qaboos University Medical Journal, 14, 297-305.

Bates, L., Filtness, A. \& Watson, B., 2018. Driver Education and Licensing Programs. In D. Lord \&

S. Washington (eds.) Safe Mobility: Background, Challenges and Solutions. Bingley: Emerald Group Publishing.

Bates, L., Rodwell, D. \& Matthews, S., 2019. Young driver enforcement within graduated driver licensing systems: A scoping review. Crime Prevention and Community Safety, 21, 116-135.

Bates, L., Scott-Parker, B., Allen, S. \& Watson, B., 2016. Young driver perceptions of police traffic enforcement and self reported driving offences. Policing: An International Journal of Police Strategies and Management, 39, 723-739.

Bates, L., Soole, D. \& Watson, B., 2012. The effectiveness of traffic policing in reducing traffic crashes. In T. Prenzler (ed.) Policing and Security in Practice: Challenges and Achievements. Basingstoke: Palgrave Macmillan.

Begg, D.J., Brookland, R. \& Connor, J., 2017. Associations of repeated high alcohol use with unsafe driving behaviors, traffic offenses, and traffic crashes among young drivers: Findings fromthe New Zealand Drivers Study. Traffic Injury Prevention, 18, 111-117.

Belsham, D., Bates, L., Somoray, K. \& Lennon, A., in press. Novice drivers and parents: Exploring the feasibility of third party policing in reducing young driver offending. Crime Prevention and Community Safety.

Blackman, R., Cheffins, T. \& Veitch, C., 2008. Young driver restrictions: Does the evidence support them? Australian Journal of Rural Health, 16, 332-337.

Brookland, R. \& Begg, D.J., 2014. Views, compliance and enforcement of Graduated Driver Licence Conditions: Findings from the New Zealand Drivers Study. Proceedings of the 2014 Australasian Road Safety Research, Policing \& Education Conference. Melbourne, Australia.

Cassarino, M. \& Murphy, G., 2018. Reducing young drivers' crash risk: Are we there yet? An ecological systems-based review of the last decade of research. Transportation Research Part F: Traffic Psychology and Behaviour, 56, 54-73.

Castillo-Manzano, J., Castro-Nuno, M., Lopez-Valpuesta, L. \& Pedregal, D., 2019. From legislation to compliance: The power of traffic law enforcement for the case study of Spain. Transport Policy, 75, 1-9. 
Chapman, E.A., Masten, S.V.\& Browning, K., 2014. Crash and traffic violation rates before and after licensure for novice California drivers subject to different driver licensing requirements. Journal of Safety Research, 50, 125-138.

Curry, A., Pfeiffer, M. \& Elliott, M.R., 2017. Compliance with and enforcement of graduated driver licensing restrictions. American Journal of Preventive Medicine, 52, 47-54.

Davey, J. \& Freeman, J., 2011. Improving road safety through deterrence-based initiatives : A review of research. Sultan Qaboos University Medical Journal, 11, 312-320.

De Waard, D. \& Rooijiers, T., 1994. An experimental study to evaluate the effectiveness of different methods and intensities of law enforcement on driving speed on motorways. Accident Analysis \& Prevention, 26, 751-765.

Elliott, M. \& Broughton, J., 2004. How methods and levels of policing affect road casualty rates. London: T. Limited, PR SE/924/04.

Etienne, J., 2011. Compliance theory: A goal framing approach. Law \& Policy, 33, 305-333.

Factor, R., 2014. The effect of traffic tickets on road traffic crashes. Accident Analysis \& Prevention, 64, 86-91.

Ferris, J., Mazerolle, L., King, M., Bates, L., Bennett, S. \& Devaney, M., 2013. Random breath testing in Queensland and Western Australia: Examination of how the random breath testing rate influences alcohol related traffic crash rates. Accident Analysis \& Prevention, 60, 181188.

Fleiter, J., Lewis, I. \& Watson, B., Year. Promoting a more positive traffic safety culture in Australia: Lessons learnt and future directionsed.^eds. Australasian College of Road Safety Conference, Adelaide, South Australia.

Freeman, J., Armstrong, K., Truelove, V. \& Szogi, E., 2015. Left on the side of the road? A review of deterrence-based theoretical developments in road safety. 2015 Australasian Road Safety Conference. Gold Coast, Australia.

Freeman, J., Kaye, S.-A., Truelove, V. \& Davey, J., 2017a. Age, gender and deterrability: Are younger male drivers more likely to discount the future? Accident Analysis \& Prevention, 104, 1-9.

Freeman, J., Kaye, S.-A., Truelove, V. \& Davey, J., 2017b. Is there an observational effect? An exploratory study into speed cameras and self-reported offending behaviour. Accident Analysis \& Prevention, 108, 201-208.

Freeman, J., Szogi, E., Truelove, V. \& Vingilis, E., 2016. The law isn't everything: The impact of legal and non-legal sanctions on motorists' drink driving behaviors. Journal of Safety Research, 59, 53-60.

Freeman, J. \& Watson, B., 2006. An application of Stafford and Warr's reconceptualisation of deterrence to a group of recidivist drink drivers. Accident Analysis \& Prevention, 38, 462 471.

Greydanus, D., 2018. The killing on the roads. International Journal of Child and Adoelscent Health, $11,145-173$.

Homel, R., 1988a. Policing and Punishing the Drinking Driver: A Study of General and Specific Deterrence New York: Springer-Verlag.

Homel, R., 1988b. Random breath testing in Australia: A complex deterrent. Australian Drug and Alcohol Review, 7, 231-241.

Mazerolle, L., 2014. The power of policing partnerships: sustaining the gains. Journal of Experimental Criminology, 10, 341-365.

Mazerolle, L., Bates, L., Bennett, S., White, G., Ferris, J. \& Antrobus, E., 2015. Optimising the length of Random Breath Tests: Results from the Queensland Community Engagement Trial. Australian and New Zealand Journal of Criminology, 48, 256-276. 
Mazerolle, L., Bennett, S., Davis, J., Sargeant, E. \& Manning, M., 2013. Procedural justice and police legitimacy: A systematic review of the research evidence. Journal of Experimental Criminology, 9, 245-274.

Mazerolle, L. \& Ransley, J., 2005. Third Party Policing Cambridge: Cambridge University Press.

Murphy, K. \& Tyler, T., 2008. Procedural justice and compliance behaviour: The mediating role of emotions. European Journal of Social Psychology, 38, 652-668.

Nunn, J., online first, 2018. The criminal histories of drug-drive offenders. Policing: A Journal of Policy and Practice.

Palumbo, A., Pfeiffer, M., Elliott, M.R. \& Curry, A., 2018. Young driver compliance with graduated driver licensing restrictions before and after implementation of a decal provision. Journal of Adolescent Health, 62, 612-617.

Paternoster, R. \& Piquero, A., 1995. Reconceptualizing deterrence: An empirical test of personal and vicarious experiences. Journal of Research in Crime and Delinquency, 32, 251-286.

Piquero, A. \& Paternoster, R., 1998. An application of Stafford and Warr's reconceptualization of deterrence to drinking and driving. Journal of Research in Crime and Delinquency, 35, 3-39.

Piquero, A. \& Pogarsky, G., 2002. Beyond Stafford and Warr's Reconceptualization of Deterrence Personal and Vicarious Experiences, Impulsivity, and Offending Behavior.

Poirier, B., Blais, E. \& Faubert, C., 2018. Graduated driver licensing and differential deterrence: The effect of license type on intentions to violate road rules. Accident Analysis \& Prevention, 110, 62-70.

Prenzler, T., Manning, M. \& Bates, L., 2015. The implications of a harm perspective on terrorism, road safety, tobacco, alcohol, illicit drugs and workplace health and safety. Journal of Policing, Intelligence and Counter Terrorism, 10, 88-101.

Reisig, M., Tankebe, J. \& Mesko, G., 2014. Compliance with the law in Slovenia: The role of procedural justice and police legitimacy. European Journal on Criminal Policy and Research, 20, 259-276.

Rose, G., 2000. The criminal histories of serious traffic offenders. London: Home Office.

Sargeant, E., Murphy, K. \& Madon, N., 2018. Is dissatisfaction with police inevitable? Testing an integrated model of motivational postures and procedural justice in police-citizen contacts. Police Practice and Research: An international journal, 19, 125-137.

Scott-Parker, B., Goode, N. \& Salmon, P., 2015. The driver, the road, the rules . . and the rest? A systems-based approach to young driver road safety. Accident Analysis \& Prevention, 74, 297-305.

Scott-Parker, B. \& Rune, K., 2016. Review of the graduated licensing programs in Australasia. Journal of the Australasian College of Road Safety, 27, 15-22.

Scott-Parker, B., Watson, B., King, M. \& Hyde, M., 2011. Mileage, Car Ownership, Experience of Punishment Avoidance, and the Risky Driving of Young Drivers,. Traffic Injury Prevention, 12, 559-567.

Scott-Parker, B., Watson, B., King, M. \& Hyde, M., 2013. Comparison of self-reported driving behaviors and experiences of immediate-uptake and delayed-uptake license holders. Transportation Research Record, 2327, 19-25.

Senserrick, T.M., Boufous, S., Olivier, J. \& Hatfield, J., 2018. Associations between graduated driver licensing and road trauma reductions in a later licensing age jurisdiction: Queensland, Australia. PLoS ONE, 13, e0204107.

Shope, J.T. \& Molnar, L.J., 2003. Graduated driver licensing in the United States: Evaluation results from the early programs. Journal of Safety Research, 34, 63-69.

Stafford, M. \& Warr, M., 1993. A reconceptualization of general and specific deterrence. Journal of Research in Crime and Delinquency, 30, 123-135. 
Szogi, E., Darvell, M., Freeman, J., Truelove, V., Palk, G., Davey, J. \& Armstrong, K., 2017. Does getting away with it count? An application of Stafford and Warr's reconceptualised model of deterrence to drink driving. Accident Analysis \& Prevention, 108, 261-267.

Truelove, V., Freeman, J. \& Davey, J., 2019. "you can't be deterred by stuff you don't know about": Identifying factors that influence graduated driver licensing rule compliance. Safety Science, 111, 313-323.

Truelove, V., Freeman, J., Szogi, E., Kaye, S.-A., Davey, J. \& Armstrong, K., 2017. Beyond the threat of legal sanctions: What deters speeding behaviours? Transportation Research Part F: Traffic Psychology and Behaviour, 50, 128-136.

Tuckett, A.G., 2005. Applying thematic analysis theory to practice: A researcher's experience. Methodology, 19, 75-87.

Tudor-Owen, J., in press. The importance of 'blue shirts' in traffic policing. Policing: A Journal of Policy and Practice.

Watling, C., Palk, G., Freeman, J. \& Davey, J., 2010. Applying Stafford and Warr's reconceptualization of deterrence theory to drug driving: Can it predict those likely to offend? Accident Analysis \& Prevention, 42, 452-458.

Webster, J., 2015. Effective third-party policing partnerships or missed opportunities? Policing and Society, 25, 97-114.

Williams, A., Mccartt, A. \& Sims, L., 2016. History and current status of state graduated driver licensing (GDL) laws in the United States. Journal of Safety Research, 56, 9-15.

Woo, Y., Maguire, E. \& Gau, J., 2018. Direct and indirect effects of procedural justice on cooperation and compliance: Evidence from South Korea. Police Practice and Research: An international journal, 19, 168-185.

Wortley, R., 2011. Psychological Criminology: An integrative approach Abingdon: Routledge.

Zhu, M., Cummings, P., Zhao, S., Coben, J.H. \& Smith, G., 2015. The association of graduated driver licensing with miles driven and fatal crash rates per miles driven among adolescents. Injury Prevention, 21, e23-e27. 